\title{
A Literature Review regarding Cervical Cancer Prevention Targeting Junior and Senior High School Students
}

\author{
Tomoko Nakamura1, Ayako Sasaki² \\ ${ }^{1}$ Faculty of Nursing, Hyogo University, Kakogawa, Japan \\ ${ }^{2}$ Faculty of Nursing, Osaka Medical College, Takatsuki, Japan \\ Email: ntomoko@hyogo-dai.ac.jp
}

How to cite this paper: Nakamura, T. and Sasaki, A. (2020) A Literature Review regarding Cervical Cancer Prevention Targeting Junior and Senior High School Students. Health, 12, 932-942.

https://doi.org/10.4236/health.2020.128070

Received: July 5, 2020

Accepted: August 10, 2020

Published: August 13, 2020

Copyright $\odot 2020$ by author(s) and Scientific Research Publishing Inc. This work is licensed under the Creative Commons Attribution International License (CC BY 4.0).

http://creativecommons.org/licenses/by/4.0/

\begin{abstract}
Objective: To understand the state of education for the prevention of cervical cancer and trends in research. The subject of cervical cancer prevention will be examined. Method: Articles from the ICHUSHI Web version 5, CiNii, and PubMed databases for the period from 2009-2019 were used. Search terms used were cervical cancer, HPV/human papillomavirus, prevention, public awareness, and education. Results: 17 articles (9 Japanese and 8 English) were analyzed. The majority of students had heard of cervical cancer but did not know of the link between it and HPV. Vaccinated individuals were significantly more likely to have deeper knowledge regarding cervical cancer and HPV. Various factors affect the vaccination rate. These include knowledge of HPV and cervical cancer, age, ethnicity, the organization or location which administers the vaccine, how to breach the subject, finances, and the opinions of friends and family. In particular, consultations with parents lead to mothers recognizing the importance of the vaccine. By way of educational intervention, opinions have grown more positive about advancing awareness, being vaccinated, and having cervical cancer screenings for the future. Conclusion: The prevention of cervical cancer requires support and fostering the judgement based on sufficient awareness and adequate education. What we need is educational intervention rooted firmly in the current societal climate aimed not only at students, but at their parents as well.
\end{abstract}

\section{Keywords}

Cervical Cancer, Prevention, Junior and Senior High School Students

\section{Preface}

In Japan, the largest proportion of STI patients falls between ages $16-20$, due to 
an increase in sexual activity among young people. Furthermore, the proliferation of HPV, which is a risk factor for cervical cancer, has been lowering the age of patients in which pathological changes to the cervix are found.

In 2016, recorded deaths due to cervical cancer increased to 2710 cases. Of special note is the rate of cervical cancer in women aged 15 - 30, which has increased by 5.6 times in the past 30 years [1]. Between the ages of $15-24$, the rate has increased by 24.1 times [1]. The proliferation of HPV has brought on an increase in cervical cancer cases and a lowering trend in the age of patients, becoming a fertility issue.

As a prevention measure against cervical cancer, Japan has established a free vaccination period for students from the first year of junior high school to the first year of high school, as well as lowered the age in which free cervical cancer screening vouchers are distributed to age 20 [2]. However, rates of treatment are low when compared to those abroad, at $0.3 \%$ for HPV vaccine and $42.3 \%$ for cervical cancer screenings in 2016 [1] [3]. In light of this situation, there is concern that the problem of cervical cancer will continue to grow. Prevention of cervical cancer is an important factor in lifelong health for our youth which can help them to protect their reproductive health and avoid life-threatening conditions.

Research on HPV vaccination and educational resources concerning cervical cancer mainly focuses on college students, adult women, and parents. However, the increase of cervical cancer cases in Japanese women in their 20s demonstrates the need for investigation into the situation regarding preventative measures in junior high school students. As such, we have conducted a literature search to understand the state of cervical cancer prevention education and trends in research in order to prepare fundamental educational materials for the future.

\section{Method}

Searches were performed on the ICHUSHI Web ver 5, CiNii, and PubMed databases for literature published between 2009 and December 2018. The keywords used were cervical cancer, HPV (Human Papilloma Virus), prevention, enlightenment, education, junior high school, and high school, shown in Figure 1. The literature search returned 251 entries from ICHUSHI, 71 from CiNii, and 297 from PubMed. After excluding duplicate results, setting the criteria to research targeting junior high school students, senior high school students, and adolescents from academic journals 17 entries (9 Japanese language entries and 8 English language entries) were selected (Table 1$)$.

\section{Results}

\subsection{Summary of Target Literature}

Because the subject of this research was junior high and high school students, all 


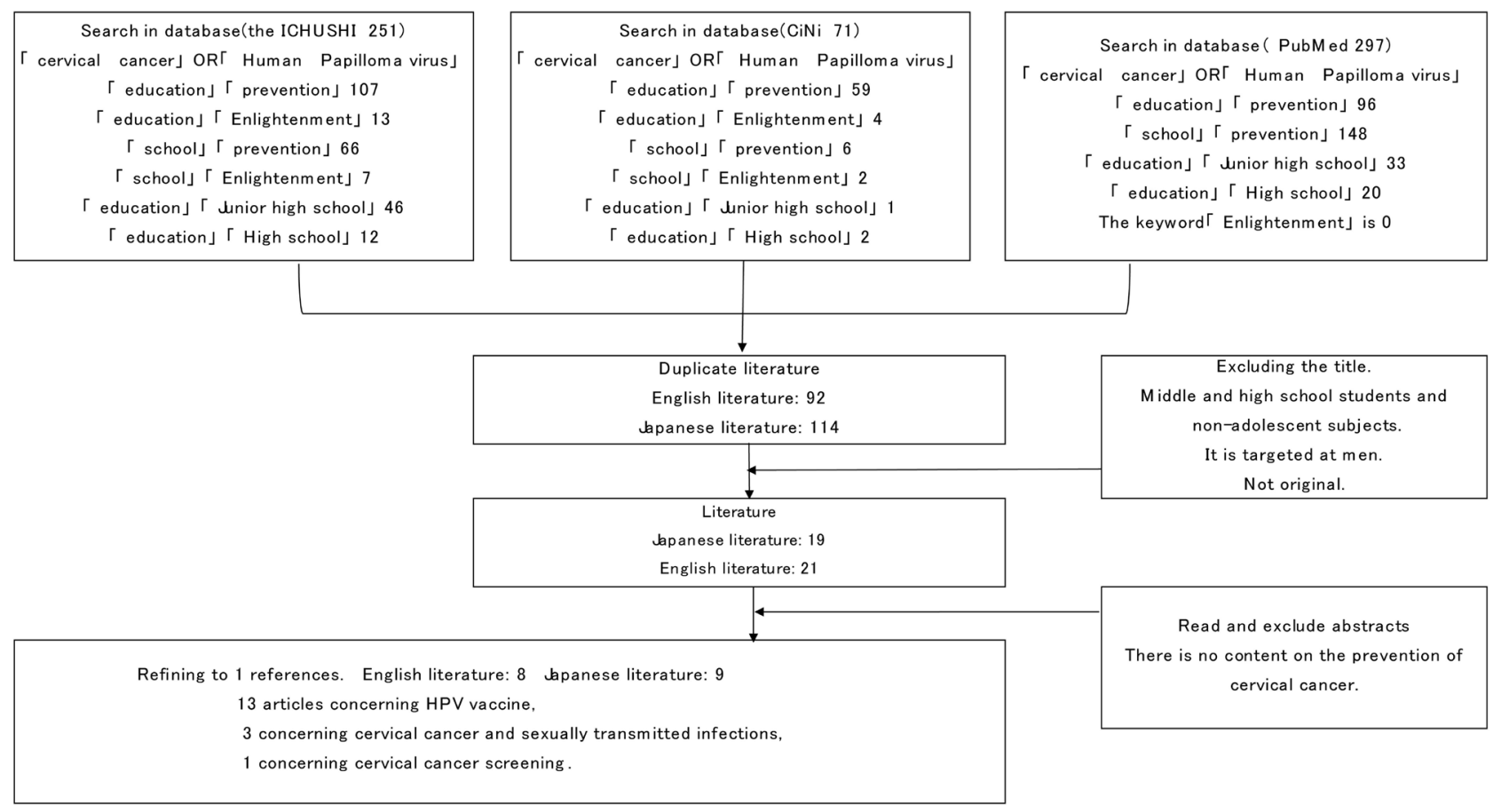

Figure 1. Literature of refinement.

target literature concerning the prevention of cervical cancer was related to HPV vaccinations.

As shown in the list of literature (Table 1), the literature referenced included the following methods: qualitative research (semi-structural interview) (1), quantitative research (16), comparison before/after execution of educational program (3), comparison of target group (6), analysis based on qualitative survey (5), analysis employing public institution surveillance (2).

13 articles were about HPV vaccination, 3 about STIs, and 1 about cervical cancer screening. The contents of the questionnaires mainly concerned awareness of HPV/cervical cancer, information sources, whether the respondent had been vaccinated and how many times, factors in deciding to be vaccinated, and comments from the respondent's parents. Some also surveyed STIs, contraceptive methods, and other vaccines.

After considering the content of the essays, results were classified into three major points (understanding of cervical cancer/HPV, state of HPV vaccination, and determining factors in subjects' intention to be vaccinated). Target literature used for analysis is listed in Table 1 and numbered [4]-[20].

\subsection{Awareness and Knowledge of Cervical Cancer/HPV}

Awareness of cervical cancer was 70.8\% - 94.0\% [11] [12] [19], while it was 5.6\% - 27.3\% [12] [16] [19] [20] for HPV. Awareness among female students was significantly higher than male students, and that of high school students higher than that of junior high school students [12]. In a survey of all 17- and 18-year-olds in Greece, no differences were found based on location (urban, 
Table 1. Citations.

\begin{tabular}{llll}
\hline NO Author & Research Design/ & Objective & Results \\
Year of & Demographic/ & \\
Publication & No. of Subjects & \\
Country & &
\end{tabular}

[4] Kwan TT et Quantitative al. $2010 \quad 953$ junior high school Hong Kong students

[5] Maya B. Quantitative Mathur et al. Survey 2010 USA 170 female high school students, grades 9 - 12

Study the vaccination decision-making process and predictive factors for vaccination.
Assess education before and after a cervical cancer education program was initiated in school.

Before the program, HPV vaccine acceptance was favorable but relevant knowledge was low. After the program, participants had greater knowledge and a more positive attitude, with more girls anticipating family ( $41.6 \%$ before vs. $58.9 \%$ after) and peer support (32.8\% before vs. $56.9 \%$ after).

Overall, $48.4 \%$ participated in the vaccination decision making and $37.8 \%$ were vaccinated, but there were significant vaccine-related knowledge gaps. Vaccination was significantly associated with older age, vaccine information sources, and higher vaccine-related knowledge, but not with estimates of risk of HPV-related diseases, religion, or frequency of health care visits.

[6] Charlene A. Quantitative Data Survey 1 - 2 years after the HPV Wong et al. Analysis 2205 girls aged 9 vaccine was approved aiming to 2011 USA $\quad-17$ understand sociodemographic behaviors, and why parents refuse to allow girls to be vaccinated.

[7] Deboran Quantitative/Comparativ Compared grade-based and Watson et e 3352 sixth grade age-based delivery methods to al. 2012 students 2180 subjects Tanzania born in 1998 determine which is more effective.

[8] KOBAYAS Qualitative/Semi-structur Study factors in vaccination HI Yuko et ed interview 26 high al. 2013 school students Japan behaviors for the prevention of cervical cancer and correlate the formed concepts to explain vaccination behaviors.

We observed increased vaccine uptake with increased age. There were no differences in HPV vaccine initiation dependent on race/ethnicity. Costs were cited as the main reason not to vaccinate daughters, and they said they would get the vaccine if it were free or provided at a much lower cost.

HPV vaccine coverage was $84.7 \%$ for dose $1,81.4 \%$ for dose 2 , and $76.1 \%$ for dose 3 . For each dose, coverage was higher in class-based schools than in age-based schools. Reasons for not vaccinating included absenteeism (6.3\%) and parent refusal (6.7\%).

The process to vaccination was affected by knowledge, awareness and perceptions of cervical cancer and the vaccine, relations with the opposite sex, and sexual activity. Barriers to vaccination and family factors were obstacles, but treatment was linked to the capacity to accommodate.

[9] Mellisa B. Quantative/Comparison Gilkey et al. of consulting, web 2014 USA consulting, and no Determine the effectiveness of the AFIX program (Assessment At the 5-month follow-up, AFIX consultations increased vaccine coverage among younger adolescents. At 1 year, the 3 arms Feedback Incentive Exchange) and showed similar coverage changes. The effectiveness of in-person consulting Data Analysis examine methods to improve the 107,434 subjects aged 11 - vaccination rate in adolescents. 18 and webinar consultations was not statistically different at either time point.

[10] SAITO Quantitative/Comparing Explore the decision-making Ryoko et al. urban and rural factors and knowledge 2014 Japan environments Questionnaire 1500 first-year high school students concerning cervical cancer among first-year high school students who received the vaccination.

The HPV vaccination coverage was $67.3 \%$. Knowledge of cervical cancer was greater in the city than rural communities, and greater in vaccinated individuals than unvaccinated individuals. Decision-making factors for getting vaccinated were recommendations from family members, if the vaccine was free or not, and the number of side effects.

Study experience with the HPV HPV vaccine coverage was $25.2 \%$, increasing in correlation to

[11] HATTORI Quantitative Study experience with the HP Keiko et al. Questionnaire 736 junior vaccine and related factors. 2014 Japan high students $\left(1^{\text {st }}-3^{\text {rd }}\right.$ year) the school grade. Associated factors were awareness of the HPV vaccine, previous experience with vaccinations, and free availability of the vaccine. The mother's opinion had the largest impact on the decision to get the shot.

[12] MIYAJI Quantitative Takami et al. Questionnaire Study the awareness of sexually transmitted disease and

$46.1 \%$ knew of public subsidization of the vaccine, $70.8 \%$ of cervical cancer, and $52.5 \%$ of the causes of sexually transmitted 2014 Japan 2205 subjects ages $9-17$ vaccinations among junior high school students.

infections, with more high school students having awareness than junior high school students, and girls more than boys. 


\section{Continued}

[13] Emilien Quantitative Data Jeannot Analysis 20,541 subjects et al. 2015 ages 11 - 19

Switzerland

[14] Kobayashi Yuko et al. 2015 Japan

Quantitative/Quest
re 1004 high school students $\left(1^{\text {st }}-3^{\text {rd }}\right.$ year $)$

[15] Sueda Chie Quantitative et al. 2015 Questionnaire 481 Japan first-year high school students

[16] Kimura Quantitative/Compariso Yoshihide et al. 2015 Japan $n$ of vaccinated vs non-vaccinated subjects 639 public junior high students

[17] Manika et al. Quantitative 2016 USA Questionnaire 889 subjects ages $14-26$

[18] FURUTA Quantitative

Kazue et al. Questionnaire 206 2016 Japan second-year junior high students

[19] Dennis Vaidakis et al. 2017

Quantitative/Urban suburban and rural Greece Questionnaire 4547 students ages 17 18 entering university
Evaluate the success of programs Coverage for girls aged 16 - 18 years at the beginning of the concerning the HPV vaccine. program reached $80 \%$ or more four years into the program. High coverage by this HPV vaccination program was likely related to free vaccination and easy access to the vaccine using a combination of delivery services, including school health services, a public hospital, and private physicians.

$78.8 \%$ of students wished to receive the HPV vaccine. Decision making factors included a positive impressions and interest in the vaccine, anxiety about the vaccine, and school grade. opinions about the cervical cancer prevention vaccine.

Study the effect in awareness of sexually transmitted infections before and after a sexual education course.

$73.9 \%$ of subjects had been vaccinated. Of these, $37 \%$ understood the possibility of being infected through sexual contact. Awareness of STIs was low before the course, but a statistically significant increase in correct answers was seen following the course.

Study awareness about the HPV $65.1 \%$ of subjects had received the HPV vaccination. Reasons vaccine and cervical cancer. included the suggestion of parents and school, and because it was available at no cost. $60 \%$ were aware of cervical cancer and the HPV vaccine. $6 \%$ were aware that HPV is a cause of cervical cancer, with no difference in knowledge between vaccinated and non-vaccinated individuals.

Study attitudes about and the adoption rate of the HPV vaccine based on level of education.

$57 \%$ and $42 \%$ of the 889 students reported starting and completing HPV vaccine series, respectively, with no statistical difference by education level. $61 \%$ of students who reported receiving a provider recommendation had completed the series, compared to $6 \%$ of those who did not receive recommendation. The belief that HPV vaccine prevents cancer was strongly associated with vaccine completion

Study the relationship between students' deciding to get vaccinated or not based on explanation from their parents.

The $50.5 \%$ of students whose parents talked to them about the HPV vaccine to them showed improved knowledge of cervical cancer. Talking about the vaccine is a good opportunity for the students to consider their sexual behavior and whether they need the vaccine.

Study awareness, attitudes, beliefs and sexual activity in More than $60 \%$ of the participants could not answer correctly neither about HPV infection and cervical cancer frequency in relation to sexual infections, with sexually active women, nor about protection methods against a focus on HPV. HPV and cervical cancer. The low vaccination coverage may be due to lack of information and awareness of the adolescents and their parents.

Students who participated in educational programs showed school student's knowledge and awareness before and after participating in an educational course about cervical cancer prevention. increased scores on a knowledge test about cervical cancer, HPV, and cervical cancer screenings. Students showed increased interest in preventative care. The percentage of students who expressed an intention to start screening when they turned 20 increased from $13.2 \%$ to $49.5 \%$.

suburban, rural) or religion [19]. Regarding high school students' knowledge of STIs, recognition was lower than that of AIDs (77.8\%) and genital herpes (75.5\%) [12]. However, among female high school students in the United States, $89.8 \%$ of vaccinated students and $7.04 \%$ of non-vaccinated students knew of the link between HPV and cervical cancer [5]. Knowledge pertaining to cervical 
cancer screening was higher among vaccinated individuals than non-vaccinated individuals, and females than males [10] [12].

Students in Japan, Hong Kong, and Switzerland who participated in sex education courses and incentive programs showed improved awareness of cervical cancer [4] [13] [15] [20]. In Japan, in a comparison of students' knowledge before and after a sex education course targeted at first-year high school students, participants showed a greater knowledge of STIs and more appropriate perceptions of sex [15]. In Japan as well as other countries, the content of these courses and incentive programs was knowledge, causes, and symptoms of cervical cancer/infection, routes of infection, time before onset of symptoms, complications, and prognoses. Content related to HPV included its relation to cervical cancer, ages at which vaccination is encouraged, screening periods, number of times, side effects, and free vouchers [4] [8] [12] [15] [20].

Regarding the source of students' knowledge, $59.9 \%$ of junior high school students said their parents or grandparents, and $52.8 \%$ said TV. $44.4 \%$ of high school students said grandparents, parents, or TV [8] [10] [11] [12] [14] [15] [16] [18] [20].

In Greece, data collection via the Internet and mobile phones is prevalent [19], while in the United States this information was provided by pediatricians and OB/GYNs which function as family doctors or by parents [5] [6] [9] [17].

\subsection{The State of HPV Vaccination}

In Japan and the United States, the percentage of students vaccinated was $25.2 \%$ - $65.1 \%$ for junior high and 50\% - 78\% for high school, increasing with each successive grade level [5] [9] [10] [11] [13] [14] [15] [16] [20]. Switzerland and Tanzania both had high rates of $80 \%$. Both countries have systems by which the vaccination can be received at schools and public institutions, and encourage vaccination through financial aid, media advertisements, and by direct mail advertising [7] [13]. Additionally, in Tanzania, comparative research based on sending materials according to school rank or date of birth found that class rank was significant to vaccination rate [7]. In countries outside of Japan, vaccination took place at schools, public hospitals, pediatricians, OB/GYNs and family practitioners [4] [6] [7] [13] [19]. However, in the United States, this was affected by a number of factors, including race, state of residence, type of medical insurance or lack thereof, lack of a family physician. This, as well as a transition of the HPV vaccination period from childhood, was connected to non-vaccination [17].

\subsection{Determining Factors in Subjects' Intention to Get the HPV Vaccine}

The determining factors of intention concerning the HPV vaccine included knowledge of cervical cancer, aggressiveness toward disease prevention, fear of cervical cancer, awareness of the possibility of contracting cervical cancer, and 
the medical experiences of people in one's social circle [4]-[18] [20]. Explanation from parents played a large part in the decision to be vaccinated, especially that from the mother [4] [6] [8] [10] [16].

Cervical cancer prevention programs targeting female high school students increased the percentage of students who intended to received screenings in the future from $13.2 \%$ to $49.5 \%$ [20]. In Hong Kong as well, following an educational program for female junior high school students, students' attitudes toward the HPV vaccine improved and students intending to be vaccinated increased by 11.3\% (from $74.9 \%$ to $86.2 \%$ ) [4]. In an American survey, the determining factors were knowledge of cervical cancer/HPV, judgement based on proper education and information, the presence of a family physician, societal trends, the opinions of friends and family, the method of approaching the subject, and financial support [5] [6] [9] [17]. Determining factors related to the HPV vaccine are shown in Figure 2. Education and information programs build awareness of the HPV vaccine and the threat of cervical cancer. Interest in cervical cancer prevention depends on the family physician and mother's explanation and approach toward the subject and is positively affected by the learning which results from acquisition of information. At the same time, it is also affected by the opinions of friends and the state of society in each country. The increase in interest toward cervical cancer prevention promotes decision-making leading to preventative behavior. Encouragement to undergo a screening, financial support, and

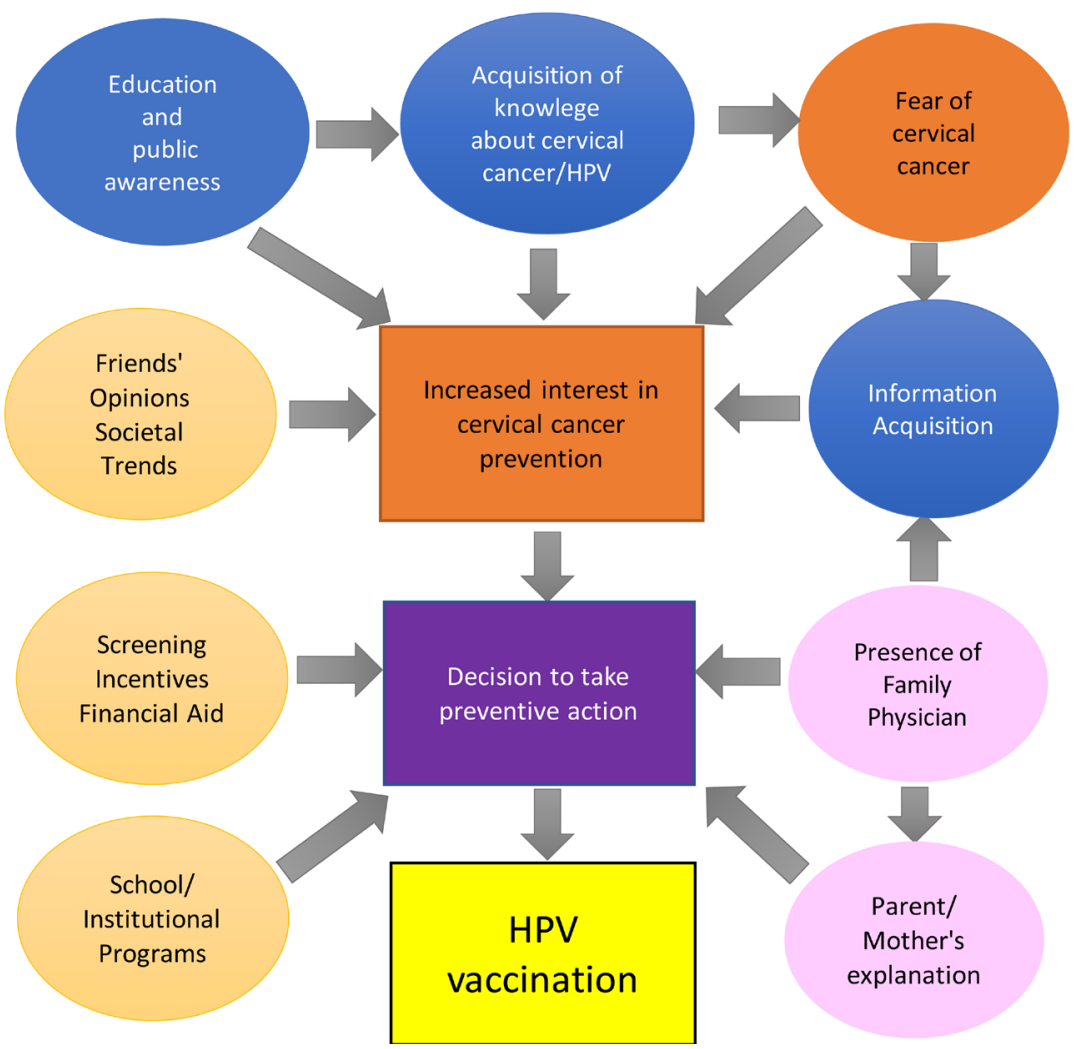

Figure 2. Outline of decision-making process for HPV vaccination. 
the establishing of schools and public institutions as places to get vaccinated are all potentiating factors for the HPV vaccine.

\section{Study}

Both the primary prevention method of vaccination and the secondary prevention method of screening are vital to the cervical cancer prevention strategy. Because the target of study was junior high and high school students, the focus was on the primary prevention method of HPV vaccination, while the topic of the secondary prevention method of cervical cancer screenings was limited to whether students had an intention to be screened in the future.

While awareness of cervical cancer among female junior high and high school students was as high at over 70\%, awareness of the link between HPV and cervical cancer was low in other countries as well as Japan. However, lectures and educational programs on cervical cancer showed signs of stimulating the vaccination rate in addition to improving awareness. In Japan, education on cancer was included in MEXT's 2009 Official Curriculum Guidelines, but on the topic of cervical cancer this only included information on screening. Similarly, even the Ministry of Health's Basic Plan to Promote Cancer Countermeasures only mentions cervical cancer screenings in the early detection through cancer screenings clause [21] [22] [23]. Since the knowledge of cervical cancer and sexual contact are related, it important to educate junior high school students with care. It was reported that in the United Kingdom the rate of parents/guardians visiting the doctor is high and education on the subject of cervical cancer and the HPV vaccine took place at home [6]. Because the source of information for over half of junior and senior high school students was their parents or grandparents, it can be said that the role of the household in passing on this information is important. If parents/guardians are able to understand and take action, the educational responsibility is born by the household and leads to preventative action.

In the majority of Western countries, vaccinations for girls around age 12 were covered by public expenses. In addition, the United States and some other countries offered the vaccine to girls starting in the latter half of their teens, when many are likely to have sexual experiences, as well as to women in their 20 $\mathrm{s}$, through a fixed-time public subsidy until the vaccination rate had increased. Countries such as Australia and Canada which offered the HPV vaccine in national programs show a decrease in HPV cases and precancerous lesions among the vaccinated generation [24]. On the other hand, the vaccination rate in Japan has dropped dramatically after active efforts to promote the vaccine ceased in 2013 due to post-vaccination side effects [25]. Side effects included pain at the injection site, redness, swelling, etc. However, these side effects are not by any means unique to the HPV vaccine. Improving vaccination rates requires not only the students' awareness, but parents' support and consent. For this reason, providing correct and trustworthy information is vital. 


\section{Conclusions}

The prevention of cervical cancer depends on the acquisition of knowledge, suitable education, and support so that informed judgements can be made. It is necessary to provide that information and opportunity. The task at hand is an approach which considers societal trends aimed at not only the patients concerned but also their parents.

There are no businesses, etc. related to COI that should be disclosed in regard to the subject presentation.

\section{Acknowledgements}

This research was conducted with financial support from the Health Science Center.

\section{Conflicts of Interest}

The authors declare no conflicts of interest regarding the publication of this paper.

\section{References}

[1] Kokuritsu Gan Kenkyū Sentaa Gan Jōhō Saabisu. Gan Tōroku/Tōkei. [National Cancer Center Cancer Information Service. Cancer Registry \& Statistics]. https:/ganjoho.jp/reg_stat/statistics/stat/summary.html

[2] Ministry of Health, Labour, and Welfare. Gan yobō jūten kenkō kyō'iku oyobi kenshin jicchi no tame no shishin, Kenhatsu dai-033010580-go [Guidelines for Emphasizing Cancer Prevention in Health Education and Screening, Health Service Bureau Notice \#0331058]. http://www.mhlw.go.jp/bunya/kenkou/dl/gan_kenshin02

[3] Ministry of Health, Labour, and Welfare. Hitopapirōmauirusukansenshō (HPV wakuchin) fukuhan'nō tsuikachōsa kekka ni tsuite [On the Results of Additional Investigation of the Side Effects of Human Papillomavirus Infection (HPV Vaccine)]. http://www.mhlw.go.jp/bunya/kenkou/kekkaku-kansenshou28/chousa/index.html

[4] Kwan, T.T., Tam, K.F., Lee, P.W., et al. (2010) The Effect of School-Based Cervical Cancer Education on Perceptions towards Human Papillomavirus Vaccination among Hong Kong Chinese Adolescent Girls. Patient Education and Counseling, 84, 118-122. https://doi.org/10.1016/j.pec.2010.06.018

[5] Mathur, M.B., Mathur, V.S. and Reichling, D.B. (2010) Participation in the Decision to Become Vaccinated against Human Papillomavirus by California High School Girls and the Predictors of Vaccine Status. Journal of Pediatric Health Care, 24, 14-24. https://doi.org/10.1016/j.pedhc.2008.11.004

[6] Wong, C.A., Berkowitz, Z., Dorell, C.G., et al. (2011) Human Papillomavirus Vaccine Uptake among 9- to 17-Year-Old Girls. National Health Interview Survey, 2008. Cancer, 117, 5612-5620. https://doi.org/10.1002/cncr.26246

[7] Watson-Jones, D., Baisley, K., Ponsiano, R., et al. (2012) Human Papillomavirus Vaccination in Tanzanian Schoolgirls: Cluster-Randomized Trial Comparing 2 Vaccine-Delivery Strategies. The Journal of Infectious Diseases, 206, 678-686. https://doi.org/10.1093/infdis/jis407

[8] Yuko, K. and Takashi, A. (2013) Joshikōsei no shikyūkeiganyobō wakuchin 
sesshukōdō ni kansuru shinrishakaiteki yō'in: shūseiban ni motozuku pasukaiseki ni yoru kentō [Factors Influencing Female High-School Students' Intention to Receive the Human Papilloma Virus Vaccine: An Investigation Using the Health Belief Model]. Gakkōkyō'ikugaku kenshū ronshū. Journal of Educational Research, 31, 13-26.

[9] Gilkey, M.B., Dayton, A.M., Moss, J.L., et al. (2014) Increasing Provision of Adolescent Vaccines in Primary Care: A Randomized Controlled Trial. Pediatrics, 134, 346-353. https://doi.org/10.1542/peds.2013-4257

[10] Ryoko, S., Koichi, T., Mutsumi, K., et al. (2014) Kō-ichi joshi no Hitopapirōmauirusuwakuchin sesshu ni taisho no yō'in [Analysis of the Factors that Influence the Inoculation of First-Year High School Girls for Human Papilloma Virus Vaccine] Hirosaki University of Health \& Welfare Journal, 5, 19-29.

[11] Keiko, H., Ayaka, O., Chie, Y., et al. (2014) Joshichūgakusei no HPV kansen yobōwakuchin sesshu keiken to sono yō'in ni kansuru kenkyū-Wakuchin sesshuritsukōjō wo mezashita keihatsu katsudō e no tei'an [A Study of HPV Vaccine Experience and Contributing Factors in Female Junior High School Students: Proposing a Public Awareness Program Aimed at Improving the Vaccination Rate]. Journal of Health and Welfare Statistics, 61, 26-32.

[12] Yoshimi, M., Ayaka, S. and Yumiko, T. (2014) Shishunki ni okeru kansenshō/ yobōsesshu ni taisuru ninshiki [Awareness of Infectious Disease and Vaccinations in Adolescence]. Osaka Society of Maternal Health Bulletin, 50, 21-30.

[13] Jeannot, E., Petignat, P. and Sudre, P. (2015) Successful Implementation and Results of an HPV Vaccination Program in Geneva Canton, Switzerland. Public Health Reports, 130, 202-206. https://doi.org/10.1177/003335491513000306

[14] Yuko, K. and Takashi, A. (2013) Joshikōsei ni okeru shikyūkeiganyobō wakuchinsesshu purosesu ni kansuru shitsutekikenkyu [A Qualitative Study of Psychosocial Factors Related to Human Papillomavirus Vaccination in Female High School Students in Kanagawa, Japan]. Journal of Japanese Society of Health Education and Health Promotion, 21, 294-306.

[15] Chie, S. and Yuki, K. (2015) Kōkōsei no sei ni kansuru chishiki to ninshiki no jittai to seikyō' ikukōza no kōka [A Study of Knowledge and Recognition of the Sexually Transmitted Diseases (STDs) for High School Students, and the Effect of Sex Education]. Bulletin of Yokohama Sōei Junior College, 2, 1-9.

[16] Yoshihide, K. and Masuko, S. (2015) Kōritsu chūgakuseito no shikyūkeigan to HPV wakuchin sesshu ni taisuru ishiki [Junior High School Girls' Awareness of Cervical Cancer and HPV Vaccines]. Ephebology, 33, 317-322.

[17] Suryadevaraa, M., Bonvillea, J.R., Klineb, R.M., et al. (2016) Student HPV Vaccine Attitudes and Vaccine Completion by Education Level. Human Vaccines \& Immunotherapeutics, 12, 1491-1497. https://doi.org/10.1080/21645515.2015.1123359

[18] Kazue, F., Kazuko, Y. and Morioka, I. (2016) HPV wakuchin no sesshu no kikai ni okeru hogosha no setsumei to shikyūkeiganyobō kōdō to no kanren -joshichugakusei no ba'ai [Relationship between Explanation from Guardians and Preventive Behaviors against Uterine Cervical Cancer at the Time of Inoculation of HPV Vaccine: A Case Involving Junior High School Girls]. Japanese Journal of Hygiene, 71, 69-75. https://doi.org/10.1265/jjh.71.69

[19] Vaidakis, D., Moustaki, I., Zervas, I., et al. (2017) Knowledge of Greek Adolescents on Human Papilloma Virus (HPV) and Vaccination: A National Epidemiologic Study. Medicine, 96, 1-7. https://doi.org/10.1097/MD.0000000000005287

[20] Miwa, I., Kazue, Y., Hisae, T., et al. (2017) Kangokeijoshidaigakusei ga jisshi shita 
joshikōkōsei e no shikyūkeigan yobō keihatsu katsudō no kōka [Effects of Education Delivered by Female Nursing Students to High School Girls about Preventing Cervical Cancer]. Ishikawa Journal of Nursing, 14, 59-69.

[21] MEXT. Chugakkō gakushu shidō yōryō kaisetsu hokentai'iku-hen (2008) [Explanation of Official Curriculum for Junior High Schools: Health and Physical Education]. Higashiyama Shobo, Kyoto.

[22] MEXT. Kōtōgakkō gakushu shidō yōryō kaisetsu hokentai'iku-hen (2009) Explanation of Official Curriculum for Senior High Schools: Health and Physical Education. Higasiyama Shobo, Kyoto.

[23] Ayako, S., Chie, S., Yumiko, H., et al. (2011) Shikyūkeigankenshin to HPV wakuchin sesshu no nichi'ei hikaku kara mieru shishunki karano kenshinkyō'iku no hitsuyōsei [The Need for Education about Health Screenings from Puberty as Revealed by a Comparison of Cervical Cancer Screenings and HPV Vaccination in Japan and Britain]. Fukui Children's Health Association Bulletin, 15, 7-21.

[24] MEXT. Gan kyō'iku. [Cancer Education]. http://www.mext.go.jp/a_menu/kenko/hoken/1370005.htm

[25] Flagg, E.W., Schwartz, R. and Weinstock, H. (2013) Prevalence of Anogenital Warts among Participants in Private Health Plans in the United States, 2003-2010: Potential Impact of Human Papillomavirus Vaccination. American Journal of Public Health, 106, 2211. https://doi.org/10.2105/AJPH.2016.303472 